\title{
Short-term memory in learning disabled and nondisabled children
}

\author{
RICHARD H. BAUER \\ Kansas State University, Manhattan, Kansas 66506
}

\begin{abstract}
In Experiment 1, children with learning disabilities and nondisabled children were presented trigrams and after a delay of $1,3,6,12$, or $18 \mathrm{sec}$ were asked to recall each trigram in serial order. They were allowed to rehearse, or rehearsal was disrupted by counting forward or backward in the delay. In Experiment 2, three words were presented and recalled either immediately or after a 30-sec delay. The results showed that, when counting was not required, recall of learning disabled and nondisabled children was not significantly different at the shortest delays but recall of learning disabled children decreased more rapidly across delays. Counting produced approximately that same relative recall decrement in both groups. The findings suggest that rehearsal may be deficient in learning disabled children.
\end{abstract}

In spite of the fact that poor learning is one of the outstanding characteristics of learning disabled children, the basis for their poor learning is not yet understood. Recently, it has -been shown that in immediate free recall, primacy of learning disabled children is lower than that of children without this disability but recency of these children is comparable (Bauer, in press; Tarver, Hallahan, Kauffman, \& Ball, in press). In delayed free recall, both recency and primacy of learning disabled children are lower than nondisabled (Bauer, in press). Since evidence from a variety of sources suggests that active rehearsal is important for adequate recall in these tasks in which learning disabled children do poorly (Atkinson \& Shiffrin, 1968; Jablonski, 1974), a rehearsal deficit may be important for the slower learning in these children (Bauer, in press; Tarver et al., in press).

Children with learning disabilities generally perform poorly in tasks thought to primarily assess attention (Dykman, Ackerman, Clements, \& Peters, 1971; Hallahan, 1975). Since attention is probably necessary for adequate learning, it has been suggested that inattention is primarily responsible for poor recall and slower acquisition in these children (Aten \& Davis, 1968; Dykman et al., 1971).

To further examine the importance of attention and memory processes for the poorer learning of these children, performance of learning disabled and normal children was compared in the Brown-Peterson task (Peterson, 1971). Since rehearsal appears to be important for short-term storage of verbal information (Atkinson \& Shiffrin, 1968; Peterson, 1971; Reitman,

This research was conducted while the author was in the UCLA Department of Psychiatry and supported by National Institute of Mental Health Grant MH-24384-01. I wish to thank the administrative and teaching staff of the UCLA Fernald School and the Los Angeles Independent School District for their cooperation and help in this research.
1974), if learning disabled children are attending to the items at the time of presentation but are not rehearsing or are rehearsing less effectively than nondisabled children, when rehearsal is not disrupted (1) recall of both groups would be expected to be similar at short delays but (2) recall of learning disabled children would be expected to decrease more rapidly as the delay between presentation and recall increases. However, if learning disabled children are not attending to the items during presentation but rehearsal is adequate, they would be expected to have a recall deficit at short delays, and the magnitude of this deficit would be expected to be relatively constant as a function of the delay.

\section{EXPERIMENT 1}

In Experiment 1, either the children were allowed to rehearse during the delay or rehearsal was impaired by counting forward or backward. The recall decrement produced by an irrelevant counting task may be important, because if children with learning disabilities do not rehearse during the delay, procedures designed to interfere with rehearsal would be expected to impair their recall to a lesser degree than nondisabled children. On the other hand, if learning disabled children rehearse some information in the delay, performance of a task which interferes with rehearsal would be expected to reduce recall as compared to when rehearsal is not disrupted.

\footnotetext{
Method

Subjects. The subjects were eight learning disabled and eight nondisabled children, matched for age (9-10 years, mean $=9.8$ ), sex (one female, seven males), and race (white). The WISC full-scale IQ of learning disabled children ranged from 80 to $104($ mean $=90.4)$ and nondisabled ranged from 97 to 109 (mean $=102: 8)$. Other characteristics of these groups have been described in detail elsewhere (Bauer, in press).
} 


\begin{abstract}
Materials and procedure. Subjects were presented a total of 60 consonant-consonant-consonant trigrams with Witmer association values no greater than $33 \%$. The trigrams were read to the child in a monotone voice at approximately 1 consonant/sec. A delay of $1,3,6,12$, or $18 \mathrm{sec}$ intervened between the last consonant and the cue for recall. The children were allowed $15 \mathrm{sec}$ to recall each trigram. The delay was either unfilled, filled by counting forward as rapidly as possible by one, or filled by counting backward as rapidly as possible by one. They were given one session of the unfilled, counting forward, or counting backward condition; across subjects, the order in which the three conditions were presented was counterbalanced. Approximately 3 days separated testing with each type of delay. In each condition each delay was given once in random order, and this procedure was repeated until the child was tested four times with each delay. A given trigram was presented only once per child.

The children were tested individually in a quiet room. They were seated at a table, with the experimenter sitting behind and slightly to the side of the child. Prior to testing with counting during the delay, the children were asked to count forward or backward to determine their maximum rate. Instructions were similar to those used previously (Peterson, 1971).
\end{abstract}

\section{Results}

The number of consonants recalled in the order given was scored and converted to percentage correct for each child and condition. Other scoring procedures were used but they yielded similar results. Figure 1 presents the mean percentage correct recall of learning disabled and normal children for each type of delay as a function of the delay length. Recall of children with normal learning was perfect at all delays with the unfilled interval. Since there was no variance within this condition and all scores were tied, a nonparametric test (Cochran's $Q$ test) was used for all statistical comparisons involving recall of normal children with the unfilled interval (twotailed test with $\mathrm{p}<.02$ for all statistical comparisons reported).

Cochran's test indicated that when, the delay was unfilled, there was no significant difference between the two groups at 1- and 3-sec delays, but learning disabled children were significantly poorer than non-

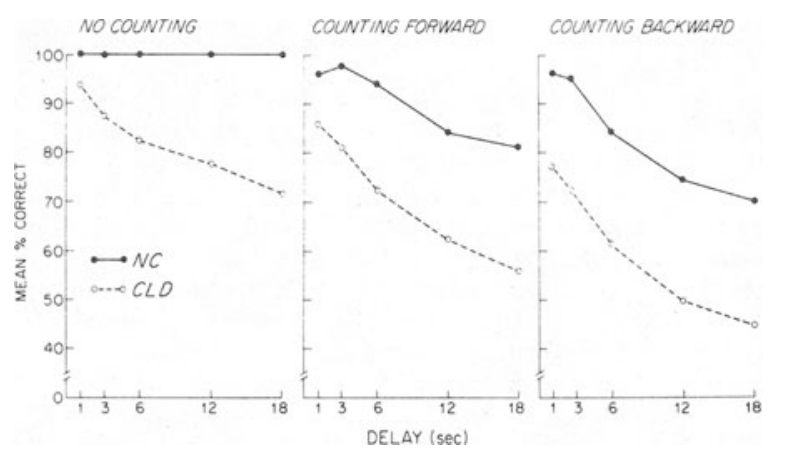

Figure 1. Mean percentage recall of normal children (NC) and children with learning disabilities (CLD) as a function of the delay. The delay interval was unfilled (left panel), filled by counting forward (middle panel), or filled by counting backward (right panel). disabled children at 6-, 12-, and 18-sec delays. MannWhitney $U$ tests showed that, when counting forward during the delay, nondisabled children were superior to children with learning disabilities at the two longest delays. When counting backward, the two groups were not significantly different from each other at the three shortest delays, but learning disabled children were significantly poorer than nondisabled children at the two longest delays.

Wilcoxon's matched-pairs signed-ranks test showed that recall of learning disabled children was significantly better at 12- and 18-sec delays when the interval was unfilled as compared to the counting forward condition. At 12- and 18-sec delays, recall of learning disabled children was inferior when the interval was filled by counting backward as compared to no counting. Learning disabled children were not significantly different when counting forward or backward at any delay.

Cochran's $\mathbf{Q}$ test showed that recall of normal children was significantly better when the interval was unfilled as compared to counting forward at 12- and 18 -sec delays. Likewise, recall of these children was significantly better at $6-, 12-$, and 18 -sec delays when the delay was unfilled as compared to counting backward. Normal learners were not significantly different from each other when counting forward or backward at any delay.

Pearson product-moment correlations were computed between IQ and total percentage recall with filled and unfilled intervals and between IQ and the rate of decline across delays (defined as the mean of the shortest delay minus the mean of the longest delay). In all cases the correlations were low and nonsignificant.

\section{EXPERIMENT 2}

Although the children in Experiment 1 were probably a representative sample of their respective populations, mean IQ of the two groups differed slightly. Since recall of children with IQs differing by as much as 30 points declines at a similar rate as a function of the delay (Belmont \& Butterfield, 1969), it appears unlikely that IQ differences are responsible for the more rapid decrement of learning disabled children across delays. This is also supported by the nonsignificant correlations between IQ and recall found in Experiment 1 . However, to insure that these findings were not due to IQ differences, children in Experiment 2 were matched for IQ.

\section{Method}

Subjects. The subjects were 13 learning disabled children and 13 children with normal learning, matched for age (all 10 years old), sex (all males), race (white), and IQ (WISC full scale, 93-115, mean $=104.9)$. These children had not participated in Experiment 1.

Materials and procedure. Eight lists of three words each were formed from the Thorndike-Lorge (1944) list. The words were monosyllabic nouns and the lists were formed so there appeared 
to be low intralist association. Each word was presented only once to each child, and they were read in a monotone voice at approximately 1 word/sec. There was either a 0 - or 30 -sec delay between the last word and the cue for recall. Each child was tested four times with each delay. Instructions and other procedures were similar to those used in Experiment 1.

\section{Results}

For each child the mean number of words correetly recalled at the 0 - and $30-\mathrm{sec}$ delays was determined for the four trials and converted to percentage correct. Since there was heterogeneity of variance across delays, the results were analyzed as in Experiment 1. Wilcoxon's matched-pairs signed-ranks test showed that children with learning disabilities recalled significantly more words with no delay (mean $=93.7 \%$ ) than after a $30-\mathrm{sec}$ delay (mean $=82.0 \%$ ). Delay length had no significant effect on recall of nondisabled children (0-sec delay, mean $=95.2 \% ; 30$-sec delay, mean $=98.7 \%$ ). Cochran's $\mathrm{Q}$ test revealed that with no delay the two groups were not significantly different from each other, but with a 30 -sec delay learning disabled were significantly poorer than nondisabled.

Correlations between IQ and recall at each delay and between IQ and the decrease across delays were not significant.

\section{DISCUSSION}

The more rapid decrement of learning disabled children as a function of the delay when the interval is unfilled is consistent with recent suggestions that rehearsal may be important for the poor short-term storage in these children (Bauer, in press; Tarver et al., in press). As discussed above, the finding that counting resulted in approximately the same relative impairment in both learning disabled and nondisabled children is consistent with the possibility that learning disabled children may be attempting to rehearse but are doing so less effectively. However, deficient retrieval cannot be excluded as the basis for these findings.

Since recall of both groups is comparable at the shortest delays, it appears that, at least under conditions of the present experiment, learning disabled may be attending during list input. The similar recency of learning disabled and nondisabled groups in immediate free recall is also consistent with this possibility (Bauer, in press; Tarver et al., in press). However, these findings do not mean that inattention is not responsible for poor performance of learning disabled children in some tasks. Rather, it appears that requirements of attention-type tasks are different from those used to demonstrate learning and memory differences (cf. Dykman et al., 1971; Hallahan, 1975).

The occurrence of irrelevant stimuli in the testing environment is likely to increase as the delay becomes longer. Therefore, there is some possibility that the delay-dependent deficit of learning disabled children with unfilled delays may be the consequence of greater distractibility from irrelevant stimuli. However, recall and acquisition of learning disabled children are not inordinately affected by distracting and irrelevant stimuli (Bauer, in press; Browning, 1967). Furthermore, requiring subjects to perform an irrelevant task during the delay not only impairs rehearsal but would be expected to direct attention away from the task of retaining the trigrams (Watkins, Watkins, Craik, \& Mazuryk, 1973). Therefore, the finding that counting results in approximately the same relative deficit in both groups suggests that the memory trace of learning disabled children is not unusually vulnerable to distracting and irrelevant stimuli.
Attempts to facilitate learning in learning disabled children have usually centered on attention, perceptual, and optometric problems, since they have traditionally been thought to account for their poor learning. However, recent evidence suggests that perceptual and optometric problems may not be responsible for their underachievement and that remediation by training in these functions is unwarranted (Hammill, 1972; McGrady $\&$ Olson, 1970). Since rehearsal may be deficient in these children, attempting to enhance rehearsal and other mnemonic processes appears warranted.

\section{REFERENCES}

Aten, J., \& Davis, J. Disturbances in the perception of auditory sequence in children with minimal brain dysfunction. Journal of Speech and Hearing Research, $1968,11,236-245$.

Atkinson, R. C., \& Shiffrin, R. M. Human memory: A proposed system and its control processes. In K. W. Spence \& J. T. Spence (Eds.), The psychology of learning and motivation (Vol. 2). New York: Academic Press, 1968.

BAUER, R. H. Memory processes in children with learning disabilities: Evidence for deficient rehearsal. Journal of Experimental Child Psychology, in press.

Belmont, J. M., \& ButTERfield, E. C. The relations of short-term memory to development and intelligence. In L. P. Lipsitt \& H. W. Reese (Eds.), Advances in child development and behavior. New York: Academic Press, 1969.

Browning, R. M. Effect of irrelevant peripheral visual stimuli on discrimination learning in minimally braindamaged children. Journal of Consulting Psychology, 1967, 31, 371-376.

Dykman, R. A., Ackerman, P. T., Clements, S. D., \& Peters, J. E. Specific learning disabilities: An attentional deficit syndrome. In H. R. Myklebust (Ed.), Progress in learning disabilities (Vol. 2). New York: Grune \& Stratton, 1971.

Hallahan, D. P. Comparative research studies on the psychological characteristics of learning disabled children. In W. M. Cruickshank \& D. P. Hallahan (Eds.), Perceptual and learning disabilities in children: Psychoeducational practices. Syracuse: Syracuse University Press, 1975.

HAMmill, D. Training visual perceptual processes. Journal of Learning Disabilities, 1972, 5, 552-559.

JABLoNSK, E. M. Free recall in children. Psychological Bulletin, 1974, 18, 522-539.

MCGRADY, H. J., \& Olson, D. A. Visual and auditory learning processes in normal children and children with specific learning disabilities. Exceptional Children, 1970, 36, 581-589.

Peterson, L. R. Short-term memory. In R. C. Atkinson (Ed.), Readings from Scientific American: Contemporary psychology. San Francisco: W. H. Freeman, 1971.

Reitman, J. S. Without surreptitious rehearsal, information in short-term memory decays. Journal of Verbal Learning and Verbal Behavior, 1974, 13, 365-377.

Tarver, S. G., Hallahan, D. P., Kauffman, J. M., \& BALL, D. W. Verbal rehearsal and selective attention in children with learning disabilities: A developmental lag. Journal of Experimental Child Psychology, in press.

THORNDIKE, E. L., \& LORGE, I. The teacher's word book of 30,000 words. New York: Teacher's College, Columbia University Press, 1944.

Watkins, M. J., Watkins, O. C., Craik, F. I. M., \& MAZURYK, G. Effects of nonverbal distraction on shortterm storage. Journal of Experimental Psychology, 1973, 101, 296-300.

(Received for publication March 25, 1977.) 